\title{
GESTÃO DE CUSTOS AMBIENTAIS NO SETOR PÚBLICO: ESTUDO DE CASO EM ORGANIZAÇÕES MILITARES NO RIO GRANDE DO SUL ENVIRONMENTAL COST MANAGEMENT IN PUBLIC SECTOR: CASE STUDY IN MILITARY ORGANIZATIONS IN RS/BRAZIL
}

\author{
Alexandre Fernandes Monteiro ${ }^{1}$ \\ Lucas Seffrin Zorzo ${ }^{2}$ \\ Marcos Antonio Souza ${ }^{3}$ \\ Nyalle Barboza Matos ${ }^{4}$ \\ Debora Gomes Machado 5
}

\section{RESUMO}

Este trabalho se propõe a identificar, sob a ótica dos gestores das unidades pesquisadas, qual o tratamento dado aos custos ambientais, suas dificuldades de reconhecimento e de gestão ambiental. Inicialmente, o estudo identificou em quais custos ambientais incidem as organizações pesquisadas e foi buscar junto à literatura motivações para a manutenção de uma estrutura capaz de informar tais custos aos seus stakeholders. As unidades incidem em diversos custos ambientais, muitos deles gerados a partir de exigências legais, sem que haja a segregação e uso desta informação por parte das organizações pesquisadas. Constatou-se o desinteresse em segregar tais dados, pois os gestores entrevistados e a setorial de contabilidade da Instituição, baseados em entendimentos enviesados, não compreendem as vantagens de se utilizar tal ferramenta de gestão. Infere-se que a principal causa do desinteresse se assenta na concepção de curto prazo por parte dos gestores baseada na heurística da representatividade, na ancoragem e no efeito disponibilidade. Percebe-se a oportunidade de uso da informação sobre os custos ambientais por parte da Instituição pesquisada, no entanto é necessária a mudança de concepção de seus líderes e gestores de uma visão de curto para longo prazo no que se refere a este tema a fim de que se compreenda o seu potencial em termos de geração de valor para a organização e sociedade.

Palavras chave: Custos Ambientais. Gestão Ambiental. Exército Brasileiro. Gestão de Custos Ambientais.

Manuscript first received/Recebido em 30/01/2019 Manuscript accepted/Aprovado em: 26/07/2019

${ }^{1}$ Doutorando em Contabilidade pela Universidade deBrasília- UnB. M estreem Contabilidade pelaU niversidade do Vale do Rio dos Sinos - Unisinos. E-mail: prof.alexandremonteiro@gmail.com

${ }^{2}$ Mestre em Contabilidade pela Universidade do Vale do Rio dos Sinos - Unisinos. Professor da Universidade Regional Integrada do A lto Uruguai e das M issões. E-mail: lucaszorzo@via-rs.net

${ }^{3}$ D outor em Controladoria e Contabilidade pela Universidade de São Paulo - USP. Professor Visitante da Universidade Federal de U berlândia. E-mail: souza.marcosa@gmail.com

${ }_{4}^{4}$ Doutoranda em Contabilidade pela Universidadede Brasília - UnB. M estre em Contabilidade pela UnB. E-mail: nyallematos@hotmail.com

5 D outora em Ciências Contábeis e Administração pela U niversidade Federal do Rio Grande. Docente da Universidade Federal do Rio Grande. E-mail: debora_furg@yahoo.com.br 


\begin{abstract}
This paper proposes to identify, from the point of view of the managers of the units surveyed, the treatment given to environmental costs, their difficulties of recognition and environmental management. Initially, the study identified which environmental costs are applied to the organizations surveyed and sought in the literature possible motivations to maintain a structure capable of reporting such costs to its stakeholders. The units incur on several environmental costs, many of them generated from legal requirements, without the proper segregation and use of this information by the organizations surveyed. It was observed a lack of interest in segregating such data, since the managers interviewed and the accounting sector of the Institution, based on skewed understandings, do not understand the advantages of using such a management tool. It is inferred that the main cause of the disinterest is based on the managers' short-term conception based on the heuristic of representativeness, anchorage and the availability effect. It is perceived the opportunity to use the information on environmental costs by the Institution researched, however, it is necessary to change the conception of its leaders and managers from a short to long term vision in this matter in order to understanding its potential in terms of generating value for the organization and society.
\end{abstract}

Keywords: Environmental Costs. Environmental Management. Brazilian Army. Environmental Costs Management.

\title{
1 INTRODUÇÃO
}

O crescimento populacional e o desenvolvimento econômico global são aspectos que impulsionam o uso e consumo de recursos naturais. Trata-se de recursos como matérias-primas, alimentos e energia nas suas diversas formas, todos eles relacionados diretamente com o meio ambiente, seja em sua exploração, ou em seu descarte (PNUMA, 2012). Para Tsai et al. (2011), esta relação entre sociedade e economia estende-se para além dos impactos ambientais causados, pois também interfere diretamente na imagem pública das instituições.

Nesse ambiente, conforme Chaves, Ferro (2012), surgem os Sistemas de Gestão Ambiental (SGA), como subsistemas de um sistema organizacional maior em que são internalizadas nas organizações uma sistemática de rotinas sustentáveis. Tais rotinas referem-se à organização estrutural do sistema, contemplando atividades de planejamento, matriz de responsabilidades, procedimentos e processos, recursos materiais e humanos. Para Seiffert (2008), empresas que adotam SGA(s) devem estruturá-lo pré-determinando as condições de seus produtos, serviços e processos, isto perante os respectivos impactos ambientais possíveis.

Pesquisas têm abordado as vantagens competitivas adquiridas pelas empresas que adotam SGA(s). Para Tsai et al. (2011), investir em SGA(s) gera vantagens competitivas na medida em que melhora a imagem pública. Para Fura (2013), a implantação das normas ambientais ISO 14000 permitem incremento de vendas com acesso a mercados globais que requerem o referido padrão o que incita a formação de uma gestão sustentável da cadeia de suprimentos.

Apesar de as instituições públicas, como regra geral, não realizarem receitas a partir das vendas de produtos/serviços de suas atividades operacionais, podem obter ganhos com venda de resíduos 
ou redução de custos ambientais, contribuindo com o meio ambiente e com a busca da eficiência em seus processos e no provimento de bem estar social (SEIFFERT, 2008). Como exemplo, um conjunto de unidades militares norte-americanas percebeu as vantagens em termos de custos ao readaptar as construções prediais existentes às normas ambientais e obtiveram melhoria na eficiência operacional dos edifícios (BASTIAN, 2011).

A fim de mitigar o potencial negativo do Estado brasileiro junto ao meio ambiente, o Governo institui obrigações normativas para órgãos e entidades da administração pública federal direta e indireta, conforme Decreto 5.940/2005 que trata da separação dos resíduos recicláveis descartados. Tal medida representa um avanço, considerando que o Exército Brasileiro (EB), no uso de suas diversas atribuições no país, possui potencial de prejudicar o meio ambiente, por fazer a "gestão de grandes áreas de terras, operar instalações industriais, realizar ações junto aos cidadãos brasileiro (NEVES E ROZEMBERG, 2010),

Nesse sentido, o Ministério da Defesa (MD) e o EB, instituíram normativos internos e estruturas de controle com vistas a lidarem com a gestão ambiental. Na área da defesa nacional, o Decreto $\mathrm{n}^{\circ} 5.484 / 2006$ que aprovou a Política Nacional de Defesa, amplia o conceito de defesa ao abordar estes aspectos ambientais. No caso específico do EB, a nota de coordenação $n^{\circ} 14-\mathrm{SI} .2 / 2^{\mathrm{a}} \mathrm{SCh} / \mathrm{EME}$ (BRASIL, 2013) traz diretrizes que conduzem suas unidades militares a identificarem ações que causam impactos ambientais e a atentar para a eficiência e efetividade de seus gastos, sempre em consonância com as leis e aspectos ambientais.

A partir destas constatações preliminares sobre a necessidade de se manterem SGA em instituições públicas e considerando os custos daí advindos e a necessidade de geri-los, é preciso refletir sobre a necessidade e viabilidade de implantação de um sistema voltado ao controle específico dos custos da gestão ambiental dado que a implementação de SGA. Assim, a pergunta a ser respondida nesta pesquisa é a seguinte: Qual o tratamento dado aos custos ambientais, suas dificuldades de reconhecimento e de gestão ambiental a partir da percepção dos gestores?

A resposta a tal questão pode ajudar a compreender porque o interesse sobre o tema custos ambientais tem perdido força conforme se verifica pela redução na produção de artigos constatada por Melo et al (2014), Moura et al (2012), Freitas (2012), Grzebieluckas, Campos e Selig (2010). Pode, ainda, ajudar a entender o desinteresse pelo tema no setor público ao destrinchar a forma de atuação de uma de suas instituições, dado que foram encontrados poucos artigos sobre o tema nesta pesquisa.

Considerando o EB como uma instituição pública, ressalta-se a importância da gestão ambiental que assim como no setor privado, inclui sistemas que envolvem toda a estrutura organizacional, atividades de planejamento, responsabilidade, práticas, procedimentos, processos e recursos para desenvolver, implementar, atingir, analisar criticamente e manter a política ambiental (CEZAR; PHILIPPI, 2018). Sendo assim, na medida em que o EB administra o patrimônio público e desenvolve atividades públicas, verifica-se o dever de cumprir todas as normas e direitos ambientais atribuídos.

Diante de suas atribuições, o EB e sua gestão de custos ambientais foi objeto de outras pesquisas como Cezar e Philippi (2018), Coelho, Ribeiro e Freitas (2017) e Martins (2016) que relataram diversas falhas na apuração dos custos ambientais e na gestão das Organizações Militares (OM) estudadas. Conforme ressalta Lucchese, Souza e Machado (2018), conhecer e identificar os procedimentos referentes oa descarte, tratamento e destinação dos resíduos gerados; examinar o devido registro de custos ambientais e verificar como as informações de custos ambientais são utilizadas na gestão é de suma importância para a instituição, e para os cidadãos de maneira geral. 
Diante da enormidade do setor público, suas especificidades e diversos setores de atuação e segmentos, esta pesquisa limitou-se a investigar algumas unidades da administração pública, especificamente do EB. Para isso, foram selecionadas organizações militares com características distintas: hospitalar, de artilharia, de logística, de ensino e de polícia que podem gerar impactos ambientais distintos.

Assim, delimitando o questionamento da pesquisa a este subconjunto do universo administração pública, busca-se atingir o seguinte objetivo de pesquisa: identificar sob a ótica dos gestores das unidades pesquisadas, quais os custos ambientais, suas dificuldades de reconhecimento e de gestão ambiental. A pesquisa pode, ainda, contribuir com dados sobre a gestão de custos ambientais no setor público e mais especificamente sobre o segmento militar em que, conforme Messer et al (2016), não possui estudos que comparem a custo-efetividade entre prontidão militar e proteção ao ambiente. Tal contribuição cresce de importância quando considerada a necessidade de uso de grandes áreas naturais para o treinamento militar cujo potencial de degradação ambiental pode ser de grande monta.

\section{CONCEITOS ESTRUTURANTES}

\subsection{GESTÃO DE CUSTOS AMBIENTAIS}

Para Souza, Heinen e Mezzomo (2012) os impactos ambientais desfavoráveis representam riscos que podem causar às empresas perdas financeiras, perda de reputação, reações desfavoráveis dos consumidores, da sociedade em geral, ações judiciais e perda de sustentabilidade. Assim, pode-se afirmar que tais impactos são a origem dos custos ambientais que decorrem de atividades relativas a preservar, controlar e recuperar o meio ambiente.

Hansen e Mowen (2003) subdividem os custos ambientais em de preservação ou prevenção em que os recursos são empregados para reduzir a poluição emitida ou desperdícios; de avaliação ou detecção, para avaliar se produtos ou processos estão de acordo com as normas; de falhas internas, empregados para tratar os resíduos gerados, mas que ainda não afetaram o meio-ambiente; e de falhas externas em que recursos são aplicados na reparação de danos já causados ao meio-ambiente.

Para Barata (2001), custos ambientais são aqueles relativos aos gastos com equipamentos e programas focados em controle de poluição. Outros exemplos de custos ambientais são: custos de descarte e disposição de resíduos (LIM, 2011), custos de limpeza e custos com processos judiciais (STANKO et al. 2006). A contabilidade de custos ambientais então se configura como um instrumento útil que permite a empresa um controle ao longo do tempo do total de gastos incorridos na gestão ambiental, facilitando a inserção da variável ambiental na tomada de decisão (BARATA, 2001).

Por que identificar, mensurar e registrar de forma segregada custos que, de acordo com as definições, são classificados como ambientais? Se são custos e neles deve-se incidir por obrigação emanada das normas e/ou para se evitar o impacto negativo na imagem da organização, por que dar a esta modalidade de custo um caráter específico de análise? Para Barata (2001), corretamente inventariados e alocados, os custos ambientais podem fazer a diferença em termos de lucratividade, na melhoria de processos e na viabilidade de longo prazo do produto.

No setor público, a adoção de sistemas e gestão que favoreçam práticas sustentáveis e de desenvolvimento social funciona como inspiração e difusão de iniciativas e políticas socialmente responsáveis, funcionando como "condutor" de bons exemplos para a sociedade (MOURA; RIBEIRO; MONTEIRO, 2017). Dessa forma, ser socialmente responsável tornou-se um compromisso passou a 
integrar a estratégia das organizações, quer privadas, quer públicas, não se limitando ao cumprimento de todas as imposições legais, mas indo além dessas obrigações sendo, portanto, um comportamento voluntário (MOURA; RIBEIRO; MONTEIRO, 2017).

Em alguns casos, conforme Hansen e Mowen (2001), os custos ambientais podem representar parcela relevante do total de custos de produção. A gestão eficiente utiliza-se de controles capazes de reduzir ou eliminar tais custos, no entanto, para isso, os custos ambientais devem ser segregados e comparados à rentabilidade da empresa (HANSEN; MOWEN, 2001). Para Tsai et al. (2011), a gestão ambiental possui custos e benefícios intangíveis que o uso do ABC pode auxiliar no processo de atribuição de valores para permitir comparação entre os custos e benefícios ambientais. Para Turturea e Turcu (2013), a adoção do ABC (Activity Based Costing) proporciona aos gestores apuração de custos mais precisa dos objetos custeados, auxiliando na identificação de elementos de gastos ambientais que podem ser administrados, senão excluídos.

Como exemplo do uso do ABC na identificação de custos ambientais, a pesquisa de Rosa, Mathias e Komata (2015) em hospital público identificou que a mão-de-obra representa o maior custo no tratamento de resíduos de serviços de saúde (RSS). Após mensurar por meio do ABC, verificou ser a etapa de acondicionamento (40,68\% dos custos) a maior consumidora de recursos, seguida pela segregação (40,17\%), o que se justifica por estarem associados aos salários da mão-de-obra de profissionais da saúde. Hansen e Mowen (2003) reforçam a ideia dos benefícios econômicos da gestão ambiental e propõem um modelo de relatório ambiental com caráter financeiro, conforme o quadro a seguir:

Quadro 1 - Proposta de Demonstração Financeira Ambiental
\begin{tabular}{|l|c|}
\hline \multicolumn{1}{|c|}{ Descrição } & Valores \\
\hline Benefícios ambientais & $\ldots$ \\
Reduções de custos ambientais & $\ldots$ \\
Receitas de reciclagem & $\ldots$ \\
\hline Custos ambientais & $\ldots$ \\
Custos de prevenção & $\ldots$ \\
Custos de detecção & $\ldots$ \\
Custos de falhas internas & $\ldots$ \\
Custos de falhas externas & $\ldots$ \\
\hline
\end{tabular}

Fonte: adaptado de Hansen e Mowen (2003)

Relatórios ambientais de caráter financeiro permitem aos gestores fazerem avaliações e controle dos impactos dos custos e benefícios ambientais na rentabilidade da empresa. Man, Răvaş e Măcriş (2012) defendem que comparar os possíveis custos e os respectivos ganhos com investimentos em gestão ambiental ou tecnologias limpas permitem avaliações comparativas da viabilidade financeira de diferentes alternativas possíveis. Assim os gestores podem tomar decisões que melhor defendem tanto o meio ambiente quanto o resultado e o caixa das empresas.

Na discussão acerca da adoção ou não de um modelo informacional que agregue a gestão de custos ambientais, as organizações devem considerar o custo de geração da informação na elaboração e divulgação de relatório contábil-financeiro. Nesse sentido, é importante que estes custos sejam justificados pelos benefícios gerados a partir da divulgação da informação (CPC 00 R1). Portanto, os gestores e pesquisadores, ao considerarem a gestão de custos ambientais, devem ter em mente a existência de um trade-off entre custos da produção desta informação e o benefício de seu uso na gestão. 


\subsection{CUSTOS AMBIENTAIS E POLÍTICA CONTÁBIL}

A concepção de sistemas de contabilidade pode considerar o estudo da reação humana e prever as formas nas quais a informação é processada para a tomada de decisão. Pode, ainda, desenvolver estratégias para motivar e influenciar o comportamento, as aspirações e os objetivos das pessoas que dirigem a organização, pois o ser humano não age tão somente de forma racional e as suas decisões ganham quase sempre um cunho psicológico que pode induzir suas escolhas (LOPES LUCENA et al., 2011).

$\mathrm{O}$ quadro a seguir informa sobre vieses que podem interferir nas decisões de gestores, prejudicando a geração de valor da organização para investidores e credores em geral.

Quadro 2 - Viéses comportamentais passíveis de influenciar gestores acerca de decisõessobre políticas contábeis.

\begin{tabular}{|l|l|}
\hline \multicolumn{1}{|c|}{ VIÉS } & \multicolumn{1}{c|}{ DESCRIÇÃO } \\
\hline $\begin{array}{l}\text { Heurística da } \\
\text { representatividade }\end{array}$ & $\begin{array}{l}\text { Pessoas tendem a pensar sobre eventos ou objetos e a fazer julgamentos sobre eles } \\
\text { baseando-se em estereótipos previamente formados }\end{array}$ \\
\hline Excesso de confiança & $\begin{array}{l}\text { Acredita-se que os operadores da contabilidade se julguem acima da média, quando } \\
\text { forem indagados sobre o conhecimento de normas contábeis }\end{array}$ \\
\hline $\begin{array}{l}\text { Heurística da relatividade } \\
\text { (ancoragem) }\end{array}$ & $\begin{array}{l}\text { Esforço envolvido em fazer ajustes a partir da âncora (conhecimento pré-existente), } \\
\text { em uma tendência das pessoas a minimizar seu esforço cognitivo }\end{array}$ \\
\hline Efeito disponibilidade & $\begin{array}{l}\text { Heurística cognitiva em que um decisor depende do conhecimento que está } \\
\text { facilmente disponível e evita analisar alternativas ou processos distintos }\end{array}$ \\
\hline
\end{tabular}

Fonte: Lopes Lucena; Arnoud Fernandes; Gomes da Silva, 2011.

Para Lopes Lucena et al (2011), a identificação de como tais falhas cognitivas, atalhos mentais e julgamentos influenciam o processo de decisão pode ajudar indivíduos e organizações a atingirem seus objetivos a partir da construção de relatórios contábeis e da execução de procedimentos eficazes. Por isso, segundo os autores, os operadores da contabilidade têm reconhecido a necessidade de mais informações econômicas não quantificáveis geradas pelo sistema de contabilidade ou relatadas em demonstrações contábeis.

Nesse viés, a maneira como uma empresa divulga sua situação financeira forma sua política contábil (HENDRIKSEN; VAN BREDA, 1999). De acordo com estes autores, a política contábil deve levar em conta os custos e benefícios da informação financeira. De uma perspectiva ampla, não pode ficar limitada a grupos específicos, e uma política contábil nacional deve considerar o bem-estar social mais amplo. Um efeito sutil da informação é a indutância informacional (efeito de feedback) que exerce um efeito esperado sobre o comportamento de quem a recebe e também afeta decisões e ações de quem envia.

$\mathrm{Na}$ escolha da política contábil, as pessoas tendem a basear estimativas e predições em observações recentes ou disponíveis, apesar destas não representarem condições de longo prazo (HENDRIKSEN; VAN BREDA, 1999). Para Pinsky, Dias e Kruglianskas (2013), a visão de longo prazo e o engajamento da alta liderança são fatores críticos para a criação de produtos sustentáveis. Assim, as empresas, por meio de lideranças sensíveis às questões de sustentabilidade, são fundamentais para conduzir novos processos favoráveis ao desenvolvimento sustentável. A ISO 14001 estabelece que a alta direção da organização deverá submeter-se periodicamente a revisões visando ao aperfeiçoamento contínuo em seu desempenho ambiental (BARATA; KLIGERMAN; MINAYO-GOMEZ, 2007). 
Para isso, pode ser necessária a implantação de uma metodologia na organização. Algumas metodologias em uso no País, como a adotada pelo Programa de Produção Mais Limpa (Pmais) e a desenvolvida por Barata (2001), vêm contribuindo para evidenciar os ganhos econômicos provenientes da gestão ambiental nas empresas. (BARATA; KLIGERMAN; MINAYO-GOMEZ, 2007).

Barata, Kligerman e Minayo-Gomez (2007) relataram que o PmaiL, na primeira fase, aplicado em onze em organizações, gerou ganhos de R \$ 497 mil/ano, a partir da redução de 97 ton/ano de resíduos perigosos, no consumo de matéria prima (120 ton/ano), de energia (1660 Mwh/ano) e de água (120 mil mªno) com investimento de $\mathrm{R} \$ 220$ mil.

A aplicação desta metodologia em três empresas em cujo custo de manutenção da gestão ambiental não ultrapassa $2 \%$ do custo total trouxe benefícios, como a redução de gastos em energia e água e no volume de resíduos tratados, ganho de receitas com a venda direta de resíduos, redução de gastos com medidas compensatórias, multas e pagamentos de custas judiciais em decorrência do descarte de efluentes líquidos fora dos padrões da licença de operação (BARATA; KLIGERMAN; MINAYO-GOMEZ, 2007).

Para Barata, Kligerman e Minayo-Gomez (2007), o setor público deve tomar a iniciativa de implantar um sistema eficiente de gestão ambiental tendo em vista os fatores sociais associados à preservação ambiental e à saúde da população e aos efeitos da melhor utilização de recursos públicos. A Agenda Ambiental na Administração Pública (A3P), programa do Governo que busca implantar uma cultura ambiental no Setor Público, atua em conformidade com os requisitos ambientais legais, evitando potenciais custos em compensação por danos ambientais. No entanto, a viabilização das mudanças pretendidas por essa Agenda dependem do engajamento do próprio servidor e de seus dirigentes. (BARATA; KLIGERMAN; MINAYO-GOMEZ, 2007).

\section{ASPECTOS METODOLÓGICOS}

A amostra deste estudo foi selecionada dentre cerca de 600 organizações militares do EB espalhadas pelo território nacional por tipo de atividade exercida (saúde, artilharia, logística, polícia e ensino). Esta pesquisa se configura como um estudo de caso múltiplo no qual se investigou com profundidade seis unidades do EB localizadas Rio Grande do Sul/Brasil. Quanto ao objetivo, caracterizase como estudo descritivo com abordagem qualitativa do problema de pesquisa, pois não se utilizou de técnicas estatísticas para quantificar os dados em análise, mas apenas preocupou-se em descrevê-los e compará-los com a literatura que trata do tema (MARTINS; THEÓPHILO, 2009).

As unidades investigadas foram determinadas pela missão institucional que realizam, com vistas a se captar diferenciados tipos de atividades e seus potenciais de impacto no ambiente. Nesse viés foram selecionadas duas unidades com encargos logísticos, uma de saúde, uma unidade de combate usuária de equipamento pesado (veículos blindados), uma unidade de polícia e uma unidade de ensino bélico.

Os entrevistados de cada unidade compreendem os oficiais de controle ambiental. Em algumas situações, quando este militar não era capaz de responder a determinadas perguntas, como no caso das compras sustentáveis ou à gestão contábil, as questões eram dirigidas a outros profissionais, porém, sempre acompanhado do oficial de controle ambiental da unidade. Foram entrevistados, ainda, oficiais responsáveis pela condução regional (Rio Grande do Sul) da política de gestão ambiental e da política contábil da Instituição. 
A coleta de dados deu-se pela transcrição das entrevistas, pela análise de documentos fornecidos e pelas observações in loco. As perguntas que permearam as entrevistas foram elaboradas com base no referencial teórico e passaram por pré-teste com membros de outras divisões do EB.

As perguntas feitas às organizações pesquisadas tiveram por objetivo fornecer respostas às seguintes questões: (i) no que se refere às atividade-fim (uso de armamento, veículos, máquinas e equipamentos, etc) e atividade-meio (produção de lixo seco e orgânico de atividades administrativas, confecção de alimentos etc) da organização quais geram ou tem potencial de gerar impactos ambientais; (ii) quais os esforços feitos com vistas a conscientizar ou mesmo treinar os militares com o objetivo de mitigar impactos ambientais gerados pela organização; (iii) quais os esforços feitos com vistas a evitar que se incorra em impactos ambientais; (iv) quais os esforços feitos com vistas a mitigar impactos ambientais em que porventura a organização incorre; (v) há um sistema que controla de forma específica (em contas contábeis separadas) os custos ambientais; (vi) em não havendo tal controle específico, é possível rastrear os custos da gestão ambiental registrados nas contas que contabilizam os custos de forma geral.

As respostas dos entrevistados foram, conforme Bardin (2011), inseridas em uma matriz de análise de conteúdo para possibilitar uma visão sistêmica do conjunto das informações. Os documentos fornecidos e analisados (fontes secundárias) foram, decretos sobre gestão ambiental, portarias que normatizam a gestão ambiental no EB, planos de gestão ambiental do EB no estado do Rio Grande do Sul e de cada unidade pesquisada, a última prestação de contas anual (2013) das unidades pesquisadas e editais de licitação. Destaca-se que por força normativa as prestações de contas possuem uma seção específica sobre a gestão ambiental na unidade.

\section{RESULTADOS E DISCUSSÕES}

\subsection{CARACTERIZAÇÃO DAS UNIDADES PESQUISADAS}

Antes de se tentar compreender a percepção dos gestores sobre os custos ambientais como ferramenta de gestão, é preciso situar-se acerca do modelo de gestão ambiental das organizações pesquisadas e dos custos daí advindos. Foram pesquisadas seis unidades militares localizadas na Grande Porto Alegre, especializadas em áreas distintas como saúde, logística, polícia, artilharia e ensino. As unidades somam um efetivo de cerca de 3.500 militares e são responsáveis por uma área de aproximadamente 1.000 hectares em que cerca de 70\% abriga flora, fauna e recursos hídricos.

Como aduzem Campos (2003) e Neves e Rozemberg (2010), pode-se constatar que todas as unidades visitadas possuem um conjunto de atividades comuns com potencial de provocar impactos ambientais. Tais impactos correspondem à produção de resíduos sólidos (papel, papelão, latas, plásticos, lâmpadas, lubrificantes, pneus, eletroeletrônicos), de lixo orgânico (alimentos, óleo de cozinha), lançamento de dejetos no esgoto, queima de lenha para produção de energia, lixo hospitalar com origem em pequenos postos de saúde/enfermarias, dentre outros. Por sua vez, algumas destas unidades, como o hospital militar e a unidade de artilharia possuem características específicas que lhe atribuem um potencial diferenciado de impacto ambiental, como produção de lixo contaminante gerado em bloco cirúrgico, deslocamento de máquinas e equipamentos pesados, disparo de munição de grande calibre (obuses, canhões, morteiros), dentre outros. 
As atividades de gestão ambiental nas unidades pesquisadas são reguladas por um Plano de Gestão Ambiental (PGA). Esse documento baseia-se no PGA para a área da $3^{\text {a }}$ Região Militar (Rio Grande do Sul) que tem por referência as diretrizes emanadas da Diretoria do Patrimônio Imobiliário e Meio Ambiente do EB (DPIMA) e normas que vão desde a Constituição Federal/1988, incluindo também a Política Nacional do Meio Ambiente (BRASIL,1981), a Política Nacional de Resíduos Sólidos (BRASIL, 2010), o Sistema de Gestão Ambiental do EB -SIGAEB (BRASIL, 2007) e a Resolução CONAMA 237/97 sobre aspectos do licenciamento ambiental (BRASIL, 1997). Todas as unidades pesquisadas possuem PGA.

Embora Neves e Rozemberg (2010) relatem que o SIGAEB foi desenvolvido com base nas normas ISO 14000, nenhuma das unidades pesquisadas fez menção a este padrão de gestão ambiental. Outras evidências destacadas nas entrevistas e observações levam ao entendimento de que as unidades pesquisadas adotam práticas ambientais apenas para cumprir leis federais ou normas institucionais. Logo, se para o EB a sustentabilidade tornou-se uma exigência (BEUREN, SANTOS, GUBIANI, 2013), não se dá pelo fato de obter vantagens competitivas tal como preconiza Tsai et al. (2011), até por que, como discorre Fura (2013) sobre o incremento de vendas com boa imagem pública devido postura sustentável, ao EB não é aplicável uma vez que sua geração de caixa depende do orçamento definido pela União.

Verificou-se que o EB instituiu seu próprio sistema de gestão de custos (Sistema Gerencial de Custos do Exército - SISCUSTOS) por intermédio da Portaria $n^{\circ}$ 932/2007. Para Carneiro Jr, Silva e Rocha (2012), o objetivo do SISCUSTOS é constituir-se em uma ferramenta organizacional de todo EB, servindo para aperfeiçoar a capacidade gerencial da instituição, cujo reflexo será a melhoria de sua capacidade operacional. Contudo, constatou-se, pelas entrevistas e pela leitura da Portaria 386/2008 que aprovou o SIGAEB e 932/2007 que aprovou o SISCUSTOS, não haver previsão ou qualquer menção acerca do registro ou da gestão de custos ambientais no EB. Tal situação confirmou-se pelos depoimentos de todos os entrevistados.

Assim, conforme os relatos obtidos e o estudo documental e a observação in loco, em função desta estrutura de gestão ambiental e de custos ser padronizada e devido à forma hierarquizada e baseada na disciplina utilizada pela Instituição, o objeto de pesquisa (gestão ambiental e custos) apresenta uniformidade na totalidade de suas organizações o que possibilita generalizações no âmbito da Instituição. Há pequenas diferenças nas práticas de gestão ambiental e de custos em função da especialidade da unidade que não se desviam das normas centrais, conforme verificado por meio das entrevistas.

\subsection{GESTÃO DOS CUSTOS AMBIENTAIS GERADOS PELAS UNIDADES PESQUISADAS}

Foi constatado o uso diário de caldeiras à base de lenha para o cozimento de alimentos, aquecimento de água para chuveiros e, no caso específico do hospital militar, lavagem de roupa de cama e trajes hospitalares. Apenas duas unidades, dentre as seis pesquisadas faz uso de filtro com vistas a reduzir a emissão de gás carbônico oriundo da queima de lenha. Uma destas unidades foi acionada pelo órgão municipal de controle ambiental que pediu providências, dado que a vizinhança do entorno denunciou o dano ao ambiente. Nesse caso, verifica-se a incidência em custos ambientais contingentes, conforme Barata (2001), que ao se realizarem exigem compensações financeiras futuras ou, no mínimo, impactam negativamente a imagem da Instituição. 
Ainda sobre a queima de lenhas em caldeiras, uma unidade adquire apenas lenha ecológica certificada que, a princípio produz uma reduzida emissão de gás carbônico, porém, medições da emissão do gás e dos gastos econômicos não são efetuadas. Conforme Hansen e Mowen (2003), o custo desta medida ambiental (custo de falha interna) e os benefícios daí advindos (reduções de custos ambientais) não foram avaliados pela unidade.

O potencial de impacto ambiental advindo da realização de exercícios militares varia com aspectos como tamanho do efetivo e equipamentos usados pelas tropas. Assim, unidades com efetivos maiores geram maior quantidade de resíduos durante os exercícios, e as que utilizam equipamentos pesados e com maior poder de destruição, como carros blindados, devem ter maior cuidado na realização de suas manobras. Todas as unidades preveem condutas de comportamento em campanha decorrente do retorno aos quartéis de todo e qualquer lixo gerado nos campos de instrução, o que confirmaria a disciplina do contingente mencionada por Neves e Rozemberg (2010). O custo destas condutas ambientais (preventivas e de falhas internas e externas) não são segregados no SISCUSTOS.

Uma das unidades pesquisadas faz uso de blindados que pesam até 28 toneladas, se movimentam sobre lagartas e lançam granadas explosivas em longo alcance. Esse tipo de equipamento em deslocamento consome grande quantidade de combustível poluente e destrói a cobertura vegetal. Nos exercícios de tiro, este mesmo equipamento pode causar incêndios, desbarrancar leitos de rios e matar animais silvestres. Desta forma, cuidados devem ser observados pela unidade ao planejar um exercício com este equipamento, como: (a) transportá-lo sob plataformas, reduzindo ao mínimo o seu deslocamento por meio de lagartas; (b) mantê-lo regulado com vistas a consumir apenas o combustível necessário; (c) não atirar sobre fontes de água doce e deixar equipes de combate a incêndio em condições de atuarem quando o tiro iniciar incêndio na vegetação. Estes custos de prevenção, detecção e oriundos de falhas internas ou externas não são segregados no SISCUSTOS.

O nível de detalhamento da coleta seletiva de lixo variou pouco entre as unidades. Embora um dos municípios em que estão instaladas as unidades militares pesquisadas não exija a coleta seletiva, todas as unidades separam o lixo seco do lixo orgânico, o que remete ao entendimento de que as unidades estudadas possuem estrutura similar proposta por Honorato e Henkes (2014). Nenhuma das unidades pesquisadas segrega os custos ambientais da coleta seletiva.

Acerca do lixo orgânico, todas as unidades objeto da pesquisa possuem serviço de feitio das refeições o que gera restos de alimentos. Nas cozinhas e refeitórios são produzidas e servidas quatro refeições diárias (café, almoço, jantar e ceia). As sobras e resíduos são controladas por meio de pesagem diária lançada em livro próprio com vistas a se evitar desperdícios. Em duas unidades, o material que não é consumido é vendido a peso para alimentar a criação de porcos. Os contratos geram uma pequena receita incremental e os contratados tem obrigação de recolher diariamente as sobras e resíduos gerados. Nas outras unidades, a destinação é a mesma, mas sem retorno econômico, bem como parte dos resíduos vai para local de compostagem dentro da organização. O óleo comestível usado é recolhido em recipientes apropriados e entregue para fornecedores de alimentos das unidades em um contrato informal que se encarregam de dar o devido destino.

Uma organização militar, em parceria com uma universidade local iniciou um projeto de transformar o óleo de cozinha usado em biocombustível, permitindo que duas das cinco unidades pesquisadas depositem desde 2011 este resíduo como material para o experimento. Não é feita a segregação destes custos ambientais o que poderia trazer uma comparação com as receitas advindas da venda das sobras e resíduos, do trabalho gratuito de condução deste lixo orgânico e do consequente benefício ambiental. 
Cabe um detalhamento de como se processa a gestão ambiental de pneus e baterias em face de se realizar a logística reversa, conforme preconizado na Lei de Resíduos Sólidos. Os pneus e baterias usados são conduzidos à unidade logística intermediária que entrega, mediante troca (mesmas quantidades e especificações), novos pneus e baterias aos usuários finais. A unidade intermediária estoca os pneus e baterias usados até um determinado nível, quando então os transporta e descarrega na unidade logística central que, novamente, mediante troca, entrega novos pneus e baterias. Os pneus usados ficam estocados na unidade central até se realizar um leilão que os destina a empresas que os reutilizam para finalidades como: (a) matéria-prima para construção de campos de grama sintética; (b) combustível para cimenteiras, dentre outros. As baterias usadas são recolhidas pelos próprios fornecedores que cumprem contrato baseado no edital de licitação lançado pela unidade de logística central. Nem o benefício traduzido pela redução de custos ambientais, nem o custo de prevenção daí advindo são segregados e contrapostos.

Ambas as unidades logísticas possuem o encargo de destruição dos artefatos explosivos vencidos ou falhados na área do Rio Grande do Sul. Essa atividade pode ter um grande impacto ambiental se não for levado em conta normas de segurança estipuladas nos manuais militares. Foi verificado que a área utilizada para essa atividade tem cerca de dois hectares e é rigorosamente controlada, evitandose qualquer tipo de impacto ambiental além do aceitável para esta necessidade. Nem os custos de prevenção, nem os de falhas internas ou externas, conforme Hansen e Mowen (2003) são segregados.

Em uma das unidades identificou-se a submissão de um militar do setor de aquisições em curso sobre contratações sustentáveis, o que pode ser relacionado com a integração da cadeia de suprimentos da qual Lopes, Sacomano Neto e Spers (2013) fazem referência e com a lei 8.666/1993 que dispõe sobre as compras sustentáveis para órgãos públicos. Porém, como estes cursos e palestras são ministrados por oficiais militares do próprio EB e tal custo não é segregado como custo de prevenção, a investigação não pôde identifica-los.

Quanto a outros resíduos secos não passíveis de tratamento específico, nenhuma das unidades pesquisadas cumpre o estabelecido no Decreto $n^{\circ}$ 5.940/2006 que exige aos órgãos e entidades da administração pública federal que destinem tais resíduos recicláveis às associações e cooperativas de catadores de materiais recicláveis. Tais custos ambientais não são segregados em contas específicas. Nesse caso, novamente se verifica a incidência em custos ambientais contingentes, conforme Barata (2001), que se realizam e exigem compensações futuras ou, no mínimo, impactam negativamente a imagem da Instituição.

A gestão de óleos lubrificantes veiculares usados e suas embalagens segue o previsto na Lei $\mathrm{n}^{\mathrm{o}} 12.305 / 2010$, pois todas as unidades armazenam o óleo retirado e entregam às empresas especializadas para reaproveitamento. No entanto, foi verificado que não é feita a gestão de lâmpadas e eletroeletrônicos conforme preconiza a Política Nacional de Resíduos Sólidos (Lei nº 12.305/2010) em que estes materiais deveriam ser entregues em locais especializados. Verifica-se aqui a incidência em custos ambientais contingentes que não são estimados e, portanto, não registrados no sistema de gestão de custos da Instituição.

Em resumo, as principais falhas encontradas no sistema de gestão ambiental se referem aos custos de prevenção e detecção de impactos ambientais não estão sendo computados no sistema de custos da organização; os custos ambientais de procedimentos como coleta seletiva também não estão sendo registrados; a receita de venda de sobras e resíduos, do trabalho gratuito de condução dos dejetos e consequentemente o benefício gerado por essa ação não é estimado. A falta de estimativa de passivos 
contingentes em relação aos custos que poderão vir a ocorrer também gera desequilíbrio na gestão ambiental, uma vez que a organização se esforça para evitar multas, indenizações e compensações, mas esse esforço não é contabilizado.

Das seis unidades pesquisadas, uma não associou investimentos em projetos ambientalmente corretos. Nas outras cinco unidades, foram citados projetos executados ou em andamento tratando da (i) implantação de sistema de coleta seletiva; (ii) conformação do posto de lavagem de veículos para separar óleo da água; (iii) mudança do sistema de armazenagem de combustíveis de enterrado para aéreo; (iv) adaptação de instalações para maior uso de iluminação natural; (v) implantação de um sistema para compostagem de resíduos alimentares e geração de adubo. No entanto, em apenas uma das unidades verificou-se a ciência de quanto um projeto específico havia custado ou custaria. Neste caso constatou-se a implantação de um sistema de coleta seletiva do lixo no valor aproximado de R 7 mil (custo de prevenção), desacompanhada do correspondente benefício ambiental financeiro (reduções de custos ambientais ou receitas de reciclagem) daí advindo.

No aspecto geral, pelo resultado do mapeamento dos custos da pesquisa de campo, nota-se que para as instituições pesquisadas não há um registro apropriado dos custos ambientais em específico e da contabilidade ambiental em geral. Essas constatações revelam a falta de um processo estruturado de planejamento e controle dos custos ambientais, assim como ressaltado por Lucchese, Souza, Machado (2018) quando realizaram pesquisa similar sobre custos ambientais hospitalares.

Segundo Cezar e Philippi (2018), essa falta de adequações torna-se atenuada por se tratar de um órgão público federal, pois há diretrizes e normas para o melhor cuidado com o ambiente no qual está inserido,e faz parte da função do Exército ajudar a comunidade em situações de riscos, também na dimensão social há cuidados relativos à saúde e à segurança dos próprios militares. Martins (2016), destaca que quanto a falta de interesse em reconhecer e gerir os custos ambientais, deve-se aumentar o comprometimento do pessoal da ativa com a sustentabilidade, de forma que a Instituição se atualize nesse ínterim e essa administração possa servir de inspiração aos seus servidores.

De posse dos custos e benefícios ambientais identificados e com base na literatura, o quadro a seguir oportuniza ganhos gerenciais por meio da adoção de controle financeiro por parte das unidades pesquisadas. Considerando o modelo de gestão ambiental e de custos utilizados pelo EB, entende-se ser possível replicá-lo em toda a Instituição o que ampliaria tais ganhos gerenciais.

Quadro 3 - Demonstração Financeira Ambiental aplicado às Unidades Militares Pesquisadas.

\begin{tabular}{|c|c|c|}
\hline & Descrição & Prática de Gestão Ambiental \\
\hline \multirow[b]{2}{*}{$\begin{array}{l}\text { Benefícios } \\
\text { ambientais }\end{array}$} & $\begin{array}{l}\text { Reduções } \\
\text { de custos } \\
\text { ambientais }\end{array}$ & $\begin{array}{l}\text {-Realiza economias com consumo de combustíveis, água, energia elétrica e lenha } \\
\text { - Evita ou mitiga a incidência em custos ambientais contingentes (estimativa do } \\
\text { valor evitado com multas, indenizações e compensações) } \\
\text { - Evita prejuízo à imagem da unidade/Instituição junto à comunidade por } \\
\text { lançamento de gases da queima de combustíveis (estimativa) }\end{array}$ \\
\hline & $\begin{array}{l}\text { Receitas de } \\
\text { reciclagem }\end{array}$ & $\begin{array}{l}\text { - Vende resíduos sólidos e orgânicos (latas, papéis, metais, resíduos e sobras } \\
\text { alimentares) }\end{array}$ \\
\hline
\end{tabular}




\begin{tabular}{|c|c|c|}
\hline \multirow{4}{*}{$\begin{array}{l}\text { Custos } \\
\text { ambientais }\end{array}$} & $\begin{array}{l}\text { Custos de } \\
\text { prevenção }\end{array}$ & $\begin{array}{l}\text {-Constrói posto de lavagem de veículo com separação de óleo (despesa de } \\
\text { depreciação), } \\
\text { - Implanta coleta seletiva de lixo hospitalar } \\
\text { - Aplica programa de educação ambiental } \\
\text { - Aplica sistemática de logística reversa do óleo e bateria } \\
\text { - Promove prevenção na área de destruição de explosivos e campos de tiro } \\
\text {. }\end{array}$ \\
\hline & $\begin{array}{l}\text { Custos de } \\
\text { detecção }\end{array}$ & - Realiza diagnóstico ambiental e medição diária do consumo de água e energia \\
\hline & $\begin{array}{l}\text { Custos de falhas } \\
\text { internas }\end{array}$ & $\begin{array}{l}\text { - Investimento em filtros na saída de gases oriundos da queima de lenha para } \\
\text { produção de energia }\end{array}$ \\
\hline & $\begin{array}{l}\text { Custos de falhas } \\
\text { externas }\end{array}$ & - Recuperação de áreas degradadas pelo uso de campos de instrução \\
\hline
\end{tabular}

Fonte: Dados da Pesquisa Inseridos no Modelo de Hansen e Mowen (2003)

Para ilustrar o montante em termos de custos ambientais em que incide o EB, foram medidas em 2014 algumas atividades geradoras de custos com a gestão do lixo em duas das unidades pesquisadas (batalhão de polícia e hospital militar). O primeiro incidiu em custos anuais na ordem de $\mathrm{R} \$ 56,7$ mil na manipulação de todo o seu lixo, incluindo o produzido em sua enfermaria (lixo hospitalar). O hospital militar incidiu em custos da ordem de $\mathrm{R} \$ 581$ mil apenas com o contrato com empresa responsável por receber e destinar o lixo hospitalar produzido internamente.Apesar da pequena amostra, quando considerada duas das 600 organizações militares do EB, percebe-se o potencial de ganho de qualidade na gestão se o modelo capturasse todas as informações sobre custos ambientais em toda a Instituição.

Diante desta constatação, pergunta-se quais seriam as causas para as lideranças e os gestores da Instituição não utilizarem a análise de custos ambientais como ferramenta de gestão, conforme se verificou ao longo desta seção. A seção a seguir analisa e discute a motivação para tal desinteresse.

\subsection{DIAGNÓSTICO DAS CAUSAS DO DESINTERESSE EM GERIR CUSTOS AMBIENTAIS}

Embora tais atividades possam ser relacionadas a melhoria de eficiência operacional, indo ao encontro dos resultados obtidos por Burnett e Hansen (2008), Bastian (2011) e Albertini (2014), para o EB não é possível identificar economicamente o nível de melhoria da eficiência operacional que estes dispêndios gerariam no caixa da Instituição. Isso ocorre pelo fato de que apenas uma evidência de mensuração de custos dos projetos adotados foi relatada.

Também é possível associar ao fato de uma contradição encontrada quanto a adoção do SISCUSTOS: a portaria 932/2007 que o instituiu não prevê um centro de custos ambiental, e, embora as observações in loco tenham revelado que o programa possui cadastrado um centro de custo para esta natureza, de nada adianta se nenhuma das unidades pesquisadas as utilizam, reforçando também as constatações de Faria (2010). Há ainda o fato de que a portaria 386/2008 que instituiu o SIGAEB não estabelece o que representam custos ambientais para o EB.

Provocada pelo pesquisador, a unidade de controle interno que apoia e fiscaliza as unidades objeto desta pesquisa enviou documento à DCont sugerindo a imposição da efetivação de centro de custos para acumular os custos ambientais. A Diretoria respondeu entender que cabe a cada unidade, individualmente, a ativação do centro de custos ambientais, no caso de se interessar em controlar e gerir tais custos. Isso mostra que a gestão dos custos ambientais, no momento, não é interesse da Instituição, pois se assim o fosse, entraria no rol de obrigações de registro de custos fiscalizadas pelas 
Inspetorias e exigidas pela Diretoria, conforme outros centros de custos regulados pelo Manual do Usuário do SISCUSTOS (BRASIL, 2015). Nesse caso, o EB prefere entende que a realização ou não do controle e gestão dos custos ambientais é uma decisão de cada uma de suas organizações militares.

Por que não há interesse por parte da Instituição em controlar e gerir seus custos ambientais? O desinteresse poderia ter origem em dois pontos: (i) no fato de a Instituição ter uma concepção, conforme Hendriksen e Van Breda (1999), de que o custo de produção da informação não compensa o benefício de seu uso ou (ii) por desconhecimento do potencial econômico do uso de tal informação como apoio à decisão.

Por não ter usado o centro de custos ambientais, a Instituição desconhece o impacto destes em sua execução orçamentária, portanto, infere-se que a origem do desinteresse se encontra na segunda opção (ii). Nesse caso, conforme Lopes Lucena, Arnoud Fernandes e Gomes da Silva (2011), tomou a decisão de não fixar a prática da gestão de custos ambientais baseado em aspectos comportamentais. Assim, infere-se que calcou tal decisão em estereótipos previamente formados (heurística da representatividade) ou a partir de conhecimento pré-existente (ancoragem) ou a partir do conhecimento que está facilmente disponível, evitando analisar alternativas ou processos distintos (efeito disponibilidade).

A causa para a formação de uma concepção enviesada por parte das lideranças e gestores entrevistados pode estar assentada em uma visão de curto prazo acerca da gestão de custos ambientais. Conforme Oliveira Claro e Claro (2014), resultados financeiros em investimentos voltados à sustentabilidade só apresentam retorno no longo prazo.

Nesse viés, o papel das lideranças sensíveis às questões ambientais é fundamental ao processo de desenvolvimento sustentável da Instituição (BARATA; KLIGERMAN; MINAYO-GOMEZ, 2007). Por outro lado, poder-se-ia discutir partir de qual nível da administração pública seria vantajoso economicamente fazer o controle e a gestão dos custos ambientais. Talvez, esta iniciativa só traga resultado positivo em longo prazo se adotada no âmbito de todo o ente (federal, estadual ou municipal).

\subsection{MOTIVAÇÕES PARA O EB INSTITUIR O CONTROLE E A GESTÃO DE CUSTOS AMBIENTAIS}

O EB é uma Instituição permanente e gera custos ambientais conforme aduzem Neves e Rozemberg (2012) e confirmado nesta pesquisa. Portanto, no caso da adoção de um modelo próprio ou como o de Barata (2001) adaptado ao setor público, haveria tempo para se verificar no longo prazo os efeitos positivos ou inóquos em termos de gestão advindos do controle dos custos ambientais.

A utilização do método de custeio ABC já faz parte da rotina da Instituição desde 2006, portanto, como este é o método de custeio mais indicado por diversos autores (ATKINSON et al., 2012; TSAI et al., 2011; TURTUREA; TURCU, 2013) para a contabilização dos custos ambientais, a adoção desse centro de custos não depende de adaptações de grande vulto em seu sistema de custeio, demandando pequeno esforço.

Outra motivação, apontada por Man, Răvaş e Măcriş (2012), é permitir avaliações comparativas da viabilidade financeira de diferentes alternativas possíveis, auxiliando os gestores a tomarem decisões que melhor defendem tanto o meio ambiente quanto o resultado e o caixa da Instituição. No caso de apontar efeitos positivos, além das vantagens econômicas, o pioneirismo na adoção de um modelo de gestão de custos ambientais bem-sucedido no setor público brasileiro poderia impulsionar outras instituições o que agregaria valor a imagem do EB. 


\section{CONCLUSÃO}

A pesquisa buscou identificar o uso da gestão de custos ambientais por parte do EB em 6 de suas organizações e a percepção de seus gestores e lideranças acerca desta ferramenta. Os entrevistados revelaram desinteresse em controlar e gerir separadamente os custos ambientais por desconhecerem o potencial desta ferramenta e compreenderem que se trata de custos que já estão sendo gerenciados por estarem inseridos com outros gastos já custeados, não merecendo uma abordagem própria. Dessa forma, a Instituição possui um sistema de gestão de custos que não considera a análise dos custos ambientais como ferramenta de gestão.

A partir da comparação das respostas dos gestores ambientais, de contabilidade e de custos com a literatura que trata de contabilidade comportamental (behavorial accounting research), inferiu-se que tal entendimento é enviesado (heurística da representatividade, efeito disponibilidade e ancoragem) com base em uma visão estereotipada de curto prazo que considera um conhecimento facilmente disponível e pré-existente, levando decisores e gestores a minimizarem seus esforços, evitando analisar alternativas distintas. Os gestores e decisores, por desconhecerem a gestão dos custos ambientais não a utilizam.

Percebeu-se, pela constatação de que as organizações pesquisadas incidem em diversos custos ambientais, que a Instituição tem potencial para extrair benefícios do uso dessa ferramenta de gestão, como: aperfeiçoamento de processos, conscientização ambiental por parte de seus integrantes, planejamento orçamentário contemplando o equilíbrio ambiental, noção do impacto dos gastos ambientais nos gastos totais, maior espectro nas avaliações da viabilidade financeira de projetos e ganhos intangíveis agregados à imagem da Instituição.

A implantação dessas alterações depende de uma mudança na perspectiva das lideranças sobre o tema investimento no meio-ambiente, passando a trata-lo sob a ótica do retorno de longo prazo. Tal retorno financeiro pode ser informado por meio da demonstração financeira ambiental que no caso do EB pode ser implantada a baixo custo haja vista a estrutura de gestão ambiental e de custos existente.

A busca por publicações sobre custos ambientais feita neste estudo incidiu na dificuldade apontada por artigos que mostram a redução do interesse de pesquisadores brasileiros pelo tema. Por sua vez esta pesquisa apontou que tal redução no interesse pode ter base no argumento de que as organizações, assim como EB, não se utilizam da prática de gestão de custos ambientais por razões comportamentais o que refletem no baixo número de casos a serem pesquisados.

Tal dificuldade de pesquisa, não significa inexistência de lacunas de conhecimento acerca do tema. Há oportunidades de pesquisa no sentido de expandir este mesmo objetivo de pesquisa a toda a função governamental Defesa identificando os custos ambientais, somando-os aos apontados nesta pesquisa e confirmando ou complementando as causas para o desinteresse em não registrar e gerir tais custos. Identificadas as causas do desinteresse, apresentar as vantagens financeiras em realizar tal controle da gestão. Pode-se, ainda, ampliar a pesquisa ao conjunto do Governo Federal indicando as oportunidades em termos de ganho financeiro no agregado de sua atuação junto à sociedade.

Um ponto a ser observado é o papel do órgão central de meio-ambiente do governo. É natural que ao infringir normas ambientais, os demais órgãos governamentais não façam a segregação dos custos contingentes daí advindos: se não há esforço para a se realizar a prevenção, não haverá esforço para se estimar os custos advindos da reparação (falhas externas). Ainda mais que há uma grande rotatividade no nível de liderança e retorno do esforço inercial para implantação do sistema só surgirá no longo prazo. 
Assim, entende-se que a iniciativa de exigir a adoção desse controle parta do próprio Ministério acionando o órgão central de contabilidade do Governo Federal que, julgando ser a informação relevante, passará a cobrá-lo das diversas setoriais contábeis. Tal prática poderia ser incorporada pela A3P. Por fim, o desdobramento da demonstração financeira ambiental, usada de forma adequada, evidenciaria o resultado financeiro dos esforços governamentais em busca de tornar suas ações sustentáveis. Esta prática, apresentando resultado positivo na gestão, tem, ainda, o potencial de estimular sua aplicação no setor privado.

\section{REFERENCIAS}

ALBERTINI, E. A descriptive analysis of environmental disclosure: a longitudinal study of French companies. Jornal of Business Ethics, v. 12, n. 1, p. 233-254, 2014.

ALMEIDA, R, SCATENA, L. M. LUZ, M. S. Percepção ambiental e políticas públicas - dicotomia e desafios no desenvolvimento da cultura de sustentabilidade. Ambiente \& Sociedade. São Paulo Vol. 20, n. 1 n p. 43-64 jan.-mar, 2017.

ATKINSON, A. A; KAPLAN, R. S.; MATSUMURA E. M.; YOUNG, S.M. Contabilidade gerencial: informação para a tomada de decisão e execução da estratégia. São Paulo: Atlas, 2012.

BARATA, M. M. L. Aplicação de uma estrutura contábil para apropriação dos custos ambientais e avaliação da sua influência no desempenho econômico das empresas, 2001. 239 f. Tese (Doutorado em Ciências em Planejamento Energético) -. COPPE/UFRJ, Rio de Janeiro, 2001.

BARATA, M. M. L., KLIGERMAN, D. C.; MINAYO-GOMEZ, C. A gestão ambiental no setor público: uma questão de relevância social e econômica. Ciência \& Saúde Coletiva, v. 12, n. 1, p. 165-170, 2007.

BARDIN, L. Análise de conteúdo. São Paulo: Edições 70, 2011.

BASTIAN, N. Optimizing army sustainability at Fort Bragg: a case study connecting life-cycle cost analysis with leadership in energy and environmental design for existing buildings. Engineering Management Journal, v. 23, n. 2, p. 42-53, 2011.

BEUREN, I. M.; SANTOS, V.; GUBIANI, C. A. Informações ambientais evidenciadas no relatório da administração pelas empresas do setor elétrico listadas no ISE. BASE, v. 10, n. 1, p. 55-68, 2013.

BORBA, JA; MURCIA, FR; MAIOR, CS. Fuzzy ABC: Modelando a Incerteza na Alocação dos Custos Ambientais. Revista Brasileira de Gestão de Negócios. 9, 24, 60-74, May 2007. ISSN: 1806

BORIA-REVERTER, S; et al. Los costes de la responsabilidad social corporativa en el campo medioambiental. : Corporate social responsible costs in the enviromental area. Intangible Capital. 9, 2, 459-476, Sept. 2013

BRASIL. Constituição (1988). Constituição da República Federativa do Brasil. Disponível em: <http:// www.planalto.gov.br/ccivil_03/Constituicao/Constituicao.htm>. Acesso em: 14 mai. 2014.

BRASIL. Decreto No 5.484, de 25 de Outubro de 2006. Aprova a Política de Defesa Nacional, e dá outras providências. Disponível em: <http://www.planalto.gov.br/ccivil_03/_Ato2004006/2005/Decreto/D5484.htm>. Acesso em: 24 Mai-2014. 
BRASIL. Decreto n 5.940, de 30 de Junho de 2005. Institui a separação dos resíduos recicláveis descartados pelos órgãos e entidades da administração pública federal direta e indireta, na fonte geradora, e a sua destinação às associações e cooperativas dos catadores de materiais recicláveis, e dá outras providências. Disponível em: <http://www.planalto.gov.br/ccivil_03/_Ato2004-2006/2006/Decreto/ D5940.htm>. Acesso em: 26 Mai 2014.

BRASIL. Lei N 12.305, de 2 de agosto de 2010. Institui a Política Nacional de Resíduos Sólidos; altera a Lei no 9.605, de 12 de fevereiro de 1998; e dá outras providências. Disponível em: < http:// www.planalto.gov.br/ccivil_03/_ato2007-2010/2010/lei/112305.htm>. Acesso em: 26 Mai 2014.

BRASIL. MINISTÉRIO DA DEFESA. EXÉRCITO BRASILEIRO. Nota de coordenação No 14-SI.2/2a SCh/EME de 17 de Dezembro de 2013. Ações correntes do sistema de excelência para 2014. Disponível em: 〈http://www.portalpeg.eb.mil.br/images/stories/fotos2012/fotos2014/14.pdf>. Acesso em: 24 Mai 2014.

BRASIL. MINISTÉRIO DA DEFESA. EXÉRCITO BRASILEIRO. Portaria No 386, de 9 de Junho de 2008. Aprova as instruções gerais para o sistema de gestão ambiental no âmbito do exército. Disponível em: < http://www.eb.mil.br/c/document_library/get_file?uuid=aefd9147-90bc-49d5-b0650807c9cb96e9\&groupId=10138>. Acesso em: 24 - Mai- 2014.

BRASIL. MINISTÉRIO DA DEFESA. EXÉRCITO BRASILEIRO. Portaria No 816, de 19 de Dezembro de 2003. Aprova o Regulamento Interno e dos Serviços Gerais (R-1). Disponível em: < http:// www.3icfex.eb.mil.br/content/legislacao/arquivos/port0816cmtex,de19dez2003, risg.pdf>. Acesso em: 20 de Jun 2014.

BRASIL. MINISTÉRIO DA DEFESA. EXÉRCITO BRASILEIRO. Portaria No 932, de 19 de Dezembro de 2007. Aprova as normas para o funcionamento do sistema gerencial de custos do exército. Disponível em: < http://www.2icfex.eb.mil.br/documentos/1secao/siscustos/Port\%20932 \%20 Cmt,\%20 19\%20Dez\%202007\%20Siscustos.pdf>. Acesso em: 24 - Mai-2014.

BRASIL. MINISTÉRIO DA DEFESA. Exército Brasileiro. Sistema Gerencial de Custos do Exército Brasileiro: Manual do Usuário. Brasília, DF, $1^{\circ}$.sem.2015. Disponível em:<http://legislacao.planalto. gov.br/legisla/legislacao.nsf/Viw_Identificacao/DEC\%2092.512-1986?OpenDocument $>$. Acesso em: 05 nov. 2015

BRASIL. MINISTÉRIO DO MEIO AMBIENTE. Agenda Ambiental na Administração Pública (A3P). Disponível em: http://www.mma.gov.br/responsabilidade-socioambiental/a3p. Acesso em: 24 - Mai2014

BRASIL. MINISTÉRIO DO MEIO AMBIENTE. Resolução n 237 de 19 de Dezembro de 1997. Regulamenta os aspectos de licenciamento ambiental estabelecidos na Política Nacional do Meio Ambiente. Disponível em: http://www.mma.gov.br/port/conama/res/res97/res23797.html. Acesso em: 23 abr 2014.

BRASIL. Presidência da República. Lei no 6.938/1981 de 31 de Agosto de 1981. Dispõe sobre a Política Nacional do Meio Ambiente, seus fins e mecanismos de formulação e aplicação, e dá outras providências. Disponível em: < http://www.planalto.gov.br/ccivil_03/leis/16938.htm>. Acesso em 14 mai. 2014. 
BRASIL. Presidência da República. Lei no 8.666 de 21 de Junho de 1993. Institui normas para licitações e contratos da Administração Pública e dá outras providências. Disponível em: <www.planalto.gov. br/ccivil_03/Leis/L8666cons.htm>. Acesso em: 23 abr. 2014.

BRASIL. Resolução CFC nº 1.154 de 27 de janeiro de 2009 - Entidades de Incorporação Imobiliária. Disponível em: . Acesso em: 25 maio 2012. Pronunciamento Técnico CPC 17 - Contratos de construção. 2010. Disponível em: . Acesso em: 6 maio 2015. BRASIL. Pronunciamento Técnico CPC 30 - Receitas. 2010. Disponível em: http://www.cpc.org.br/pdf/CPC_30.pdf. Acesso em: 6 maio 2012 BURNETT, R. D.; HANSEN, D. R. Ecoefficiency: defining a role for environmental cost management. Accounting, Organizations and Society, v. 33, n. 6, p. 551-581, 2008.

CAMPOS, J. C. P. A gestão ambiental no Exército Brasileiro e a sua compatibilização com o adestramento da Força. 2003. 74 f. Trabalho de conclusão de curso (Curso de Política, Estratégia e Alta Administração do Exército). Escola de Comando e Estado-Maior do Exército, Rio de Janeiro, 2003.

CARMO, L. P; SILVA, L. Custeio baseado em atividades (ABC) aplicado ao setor público: estudo de caso no colégio militar do Rio de Janeiro (CMRJ). Revista Uniabeu, v. 4, n. 6, p. 16-181, 2011.

CARNEIRO JR, M.; SILVA, W. V.; ROCHA, D. T. Custos no serviço público: o sistema gerencial de custos do exército. ABCustos, v. 7, n. 1, p. 110-131, 2012.

CEZAR, N. A. PHILIPPI, D. A. Gestão sustentável em uma organização militar no estado do Mato Grosso do Sul. Brazilian Journal of Development. Curitiba, v. 4, n. 2, p. 365-383, abr./jun. 2018.

CHAVES-FERRO, M. A. Environmental management system (EMS) for military activities - strategies and policies for american, canadian, brazilian and nato armies. International Journal of Sustainable Development, v. 5, n. 3, p. 19-32, 2012.

EB - Exército Brasileiro. disponível em: http://www.eb.mil.br/web/guest/quarteis-por-estado1, acesso em: 20 set 2016.

FARIA, C. E. P. A implantação do sistema gerencial de custos (SISCUSTOS) desenvolvido pelo Exército Brasileiro: estudo de caso na $1^{a}$ Inspetoria de Contabilidade e Finanças do Exército. Dissertação (Mestrado de Ciências Contábeis) Universidade do Estado do Rio de Janeiro. Rio de Janeiro, 2010.

FARIA, J. A. 1; MATOS, A. G.; MATA, C. R.; JESUS, R. R. J. O espaço dos custos ambientais na contabilidade: um diagnóstico entre futuros contadores e principais periódicos acadêmicos no Brasil. Revista de Estudos Contábeis, v. 4, n. 6, p. 99-122, 2013.

FENKER, E. A.; DIEHL, C. A.. ALVES, T. W. Um estudo empírico sobre gestão de custos e riscos ambientais. In: Congresso Brasileiro De Custos, 16. Anais... Fortaleza ABCUSTOS, 2009.

FREITAS, C. L. Custos ambientais: área temática ou publicações ‘isoladas'?-Uma análise das publicações do Congresso Brasileiro de Custos sob a ótica da contribuição dos pesquisadores para o desenvolvimento da temática. In: Anais do Congresso Brasileiro de Custos-ABC. 2012.

FURA, B. Improving ISO 14001 environmental management systems. Polish Journal of Environmental Studies, v. 22, n. 6, p. 1711-1721, 2013.

GRZEBIELUCKAS, C.i; CAMPOS, LMS ; SELIG, P. M.. Contabilidade e custos ambientais: um levantamento da produção científica no período de 1996 a 2007. Produção, v. 22, n. 2, p. 322-332, 2010. 
HANSEN, D. R.; MOWEN, M. M. Gestão de custos: contabilidade e controle. São Paulo: Pioneira Thomson Learning, 2003.

HENDRIKSEN, E. S.; VAN BREDA, M. F. Teoria da contabilidade; tradução de Antonio Zoratto Sanvicente. São Paulo: Atlas, p. 277-297, 1999.

HENRI, J.-F.; JOURNEAULT, M. Eco-control: the influence of management control systems on environmental and economic performance. Accounting, Organizations and Society, v. 35, n. 1, p. 63-80, 2010.

HONORATO, J. M.; HENKES, J. A. A gestão de resíduos sólidos em uma organização militar de selva. Revista Gestão \& Sustentabilidade Ambiental, v. 2, n. 2, p. 148-199, 2014.

LIM, M. Full cost accounting in solid waste management: the gap in the literature on newly industrialized countries. Journal of Applied Management Accounting Research, v. 9, n. 1, p. 21-36, 2011.

LOPES LUCENA, W. G.; ARNOUD FERNANDES, M. S.; GOMES DA SILVA, J. D. A contabilidade comportamental e os efeitos cognitivos no processo decisório: uma amostra com operadores da contabilidade. Revista Universo Contábil, v.7, n.3, p. 41-58, 2011.

LOPES, L. J.; SACOMANO NETO, M.; SPERS, V. R. E. Diferenças e complementaridades entre a logística reversa, ISO 14000 e o green supply chain management. Revista Gestão Industrial, v. 9, n. 1, p. 225-253, 2013.

LUCCHESE, A. R. SOUZA, M. A. MACHADO, D. G. Gestão de custos ambientais em organizações hospitalares da região noroeste do Rio Grande do Sul. Gestão \& Regionalidade - Vol. 34 - N¹01 maio-ago/2018.

MAN, M.; RĂVAŞ, B.; MĂCRIŞ, M. Environment costs: structure and acknowledgement: their dynamics in romania after the integration within the european union. Internal Auditing \& Risk Management, v. 7, n. 2, p. 62-85, 2012.

MARTINS, G. M.; THEÓPHILO, C. R. Metodologia da investigação científica para ciências sociais aplicadas. $2^{\mathrm{a}}$ ed. São Paulo: Atlas, 2009.

MARTINS, J. D. C. Gestão ambiental aplicada a uma organização Militar do Exército. Monografia. Universidade Federal do Rio Grande do Sul. Escola de Administração. Curso de Administração.

MELO, D. V; RAYANNE, S. B.; TAMIRES, S. A.; EDVALDA, A. L. Contabilidade e custos ambientais: Um mapeamento das produções científicas em periódicos e eventos nacionais. Revista Ambiente Contabil, v. 6, n. 1, p. 236, 2014.

MESSER, KD; KECINSKI, M.; ZHOU, L. KORCH M.; BOUNDS, T. Military Readiness and Environmental Protection through Cost-effective Land Conservation. Land Economics. 92, 3, 433449, Aug. 2016

MOURA, A. M. A. RIBEIRO, P. L. R. MONTEIRO, S. M. S. A responsabilidade social no setor público: uma perspetiva teórica sobre a Divulgação de informação. International Business and Economics Review, nº8, 2017.

MOURA, GD; FANK O.; SANCHES, J.; TOLEDO FILHO J. Perfil das pesquisas na área de gestão de custos ambientais e responsabilidade social do congresso brasileiro de custos de 2005 a 2009. Revista de Gestão Social e Ambiental. 6, 1, 161-176, Apr. 2012. 
NEVES, E. B.; PICONCELLI, M. C. A.; OLIVEIRA, S. H. K.; ROZEMBERG, B. Práticas de educação ambiental: breve diagnóstico em organizações militares do Exército Brasileiro. Ciência \& Educação, v. 18, n. 1, p. 173-186, 2012.

NEVES, E. B.; ROZEMBERG, B. Estudo comparativo entre o sistema de gestão ambiental do Exército Brasileiro e a norma ISO 14001. Revista de Gestão Social e Ambiental, v. 4, n. 1, p. 159-177, 2010.

OLIVEIRA CLARO, P. B.; CLARO, D. P. Sustentabilidade estratégica: existe retorno no longo prazo?. Revista de Administração, v. 49, n. 2, p. 291, 2014.

PINSKY, V.C.; DIAS, J. L.; KRUGLIANSKAS, I. Gestão estratégica da sustentabilidade e inovação. Revista de Administração da UFSM, v. 6, n. 3, p. 465-480, 2013.

PNUMA - Programa das Nações Unidas para o Meio Ambiente. (2012). Disponível em: http://www. pnuma.org.br/admin/publicacoes/texto/GEO5_RESUMO_FORMULADORES_POLITICAS.pdf. Acessado em: 01 Mai 2014.

RIBEIRO, P. L. R. MONTEIRO, S. M. S. MOURA, A. M. A. Determinants of sustainability e-reporting in portuguese municipalities: an institutional and legitimacy theoretical framework. Corporate Responsibility and Stakeholding Developments in Corporate Governance and Responsibility, Vol. $10, \mathrm{~N}^{\mathrm{o}} 131,2016$.

ROSA, C.D.P.; MATHIAS, D.; KOMATA, C.C. Custo de gerenciamento de resíduos de serviços de saúde (RSS): estudo de caso da unidade de terapia intensiva de infectologia de um hospital público em São Paulo. Revista de Gestão Ambiental e Sustentabilidade (GeAS). 4, 2, 127-143, May 2015.

SEIFFERT, M. E. B. Environmental impact evaluation using a cooperative model for implementing EMS (ISO 14001) in small and medium-sized enterprises. Journal of Cleaner Production, v. 16, n. 14, p. 1447-1461, 2008.

SILVA, C. R. G. Z. A gestão ambiental em exercícios de artilharia: o gerenciamento e a minimização dos impactos ambientais decorrentes de exercícios de artilharia. In: SIMPÓSIO DE EXCELÊNCIA EM GESTÃo E TECNOLOGIA, 3, 2011. Anais... Rio de Janeiro, 2011.

SOUZA, MA; HEINEN, AC; MEZZOMO, F. Planejamento e controle de custos ambientais: um estudo multicaso em indústrias do Rio Grande do Sul.. Revista de Informação Contábil. 6, 4, 62-83, Oct. 2012

STANKO, B. B.; BROGAN, E.; ALEXANDER, E.; CHAY, J. C.-M. Environmental accounting. Business \& Economic Review, v. 52, n. 3, p. 21-27, 2006.

TSAI, W.-H.; CHEN, H.-C.; LIU, J.-Y.; CHEN, S.-P.; SHEN, Y.-S. Using activity-based costing to evaluate capital investments for green manufacturing systems. International Journal of Production Research, v. 49, n. 24, p. 7275-7292, 2011.

TURTUREA, M.; TURCU, R. D. Costing systems design for sustainability. Theoretical and Applied Economics, v. 20, n. 10, p. 127-147, 2013. 